\title{
Role of Clergywomen in Promoting Preventive Breast Cancer Behaviors Among Muslim Women in Iran: A Qualitative Study
}

\author{
Minoor Lamyian $^{\text {a*iD, }}$ Fazlollah Ahmadi $^{\text {b }}$, Hosna Sheikholeslami ${ }^{\text {c }}$ \\ ${ }^{a}$ Department of Reproductive Health \& Midwifery, Faculty of Medical Sciences, Tarbiat Modares University, Tehran, Iran. \\ ${ }^{\mathrm{b}}$ Department of Nursing, Tarbiat Modares University, Tehran, Iran. \\ ${ }^{\mathrm{c}}$ Department of Anthropology and Sociology, Denison University, Granville, Ohio, USA.
}

\begin{tabular}{|c|c|}
\hline A RTICLEINFO & $A B S T R A C T$ \\
\hline ORIGINAL ARTICLE & ackground: The purpose of this qualitative study \\
\hline Article History: & $\begin{array}{l}\text { women's perceptions, behaviors, and beliefs related to breast cancer } \\
\text { screening readiness, with a focus on the role of religion. }\end{array}$ \\
\hline Received: 4 Jan 2020 & Methods: Our sample consisted of 25 women, 35 to 65 years old, who \\
\hline Revised: 15 JAN 2021 & resided in Tehran, Iran. It included 15 at-risk women (self-reported history of \\
\hline Accepted: 14 Mar 2021 & breast cancer before the age of 40 in their family) and 10 others with a history \\
\hline $\begin{array}{l}\text { *Corresponding Author: } \\
\text { Minoor Lamyian }\end{array}$ & $\begin{array}{l}\text { The women were chosen using purposive sampling. We used a qualitative } \\
\text { content analysis design with a constant comparative analysis approach, which } \\
\text { is appropriate for obtaining reliable and valid results from textual data. }\end{array}$ \\
\hline Email: & (1) \\
\hline
\end{tabular}

lamyianm@modares.ac.ir

Tel: +98 2182883809

\section{Citation:}

Lamyian M, Ahmadi F, Sheikholeslami H. Role of Clergywomen in Promoting Preventive Breast Cancer Behaviors Among Muslim Women in Iran: A Qualitative Study. Journal of Social Behavior and Community Health (JSBCH). 2021; 5(1): 652-664.
Results: The overarching theme apparent from transcript analysis was that of "Clergywoman Can Play a Role in Increasing Awareness". Four categories, namely, (1) Lack of information regarding breast cancer screening, (2) Awareness can improve self-care, (3) Religious outlooks of participants can influence early detection behaviors, (4) Clergywoman can play a role in increasing awareness, were identified. However, we found that the majority of interviewees lacked information about breast cancer screening and prevention. This was often both the cause and the effect of fear and misunderstandings about the process. Furthermore, we found that religious authorities, particularly clergywomen, who speak from a religious perspective, could play a significant and effective role in convincing women to pursue prevention measures. Additionally, we found that many women emphasized that religious gatherings, or framing health messages in a religious narrative, could be a significant step forward in advocating early detection behaviors.

Conclusion: Our study shows that religion is a motivating factor in breast cancer early detection behavior and offers new insight into women's perceptions of self-care. It highlights a potentially significant role of clergywomen in encouraging women in Tehran, Iran to pursue breast cancer screening.

Keywords: Breast Cancer,Early detection, Self-care, Women, Religion, Islam 


\section{Introduction}

In Iran, breast cancer is the most common cancer among women, as it is worldwide (Alianmoghaddam et al., 2017; Cancer Country Profiles, 2016; Cancer Facts \& Figures, 2018). Significantly, breast cancer affects Iranian women at least one decade earlier than women in developed countries (Movahedi et al.,2012). Currently, approximately one-third of breast cancer cases affect women under 40 years of age in Iran (Mousavi et al., 2008; Mousavi et al., 2007; Harirchi et al., 2000) Results from previous studies in Iran have shown that breast cancer is most prevalent among women aged 35 to 44 (Moodi et al., 2012). This prevalence means that breast cancer affects women in their peak fertile period, during which many women have significant social, occupational, and familial responsibilities (Haghighi et al., 2015). As many have noted, the disease often presents more aggressively in younger women and has a poorer prognosis (Babu et al., 2011). As such, a diagnosis of breast cancer during this period deeply affects the quality of life of women and their family members (Harandy et al., 2010). Therefore, the control and prevention of breast cancer is a serious and basic health problem in women's healthcare (Alianmoghaddam et al., 2017; Perry et al., 2007).

From 2012 to 2018, incidences of new breast cancer diagnosis have increased by 25 percent, and mortality due to breast cancer has risen by more than 13 percent worldwide (Ferlay et al., 2019; , Ferlay et al., 2015). In particular, the incidence of breast cancer is increasing in developing countries due to urbanization, longer life expectancy, and the adoption of Western lifestyles (Cancer Facts \& Figures, 2018; Mousavi-Jarrrahi et al., 2013). While developed countries have higher incidence rates, developing countries have higher mortality rates due to relatively fewer early detection measures and access to treatment facilities (Shulman et al., 2010). Similarly, the incidence of breast cancer is increasing in Iran (Bray et al., 2018).

Reflecting these global patterns, two studies in
Iran have demonstrated that $25 \%$ to $42.5 \%$ of Iranian women fail to seek medical help until three months or more after initial detection of breast symptoms (Harirchi et al., 2005; Montazeri et al., 2003). While three of five American women are diagnosed with breast cancer in the early stages, in Iran, this number is fewer than one in five (Alianmoghaddam et al., 2017; Mousavi et al., 2007). In Iran, a population-based screening mammogram is not practiced, although it is estimated that there are about 200 diagnostic mammography centers in the country (KhazaeePool et al., 2014). Early diagnoses of cancer remain limited to those well-informed patients who self-refer and the few health providers who practice opportunistic screening.

Since later detection and delayed treatment correlate to progressed stages of the disease, there are lower survival (higher mortality) rates in Iran than in developed countries, even though the overall prevalence of breast cancer is lower (Rezaianzadeh et al., 2011; Heydari et al., 2009; Montazerie et al., 2003). Early detection of the disease can reduce mortality rates and improve patient prognosis (Babu et al., 2011). According to the Guidelines of Implementation for Breast Healthcare, 'Early detection to improve breast cancer outcome and survival remains the cornerstone of breast cancer control' (Anderson et al., 2008).

Considering the low numbers of early detection of breast cancer, we focus on the factors that affect this phenomenon. Given that early detection translates to an improved prognosis, an important question arises: How can early detection be improved in developing countries such as Iran? Unfortunately, Iranian women's perceptions, behaviors, and beliefs related to readiness for early detection have not been widely explored (Noroozi et al., 2011). The purpose of this study is to explore Iranian women's perceptions, behaviors, and beliefs as related to breast cancer screening readiness, with a focus on the role of religion. Few researchers have examined the effects of religion on health education, prevention, and treatment (Nasirzadeh \& 
Rassolzadeh Tabatabaie, 2009). Even though religion and religious values undoubtedly affect preventative health behaviors, religion-related barriers or expeditors to breast cancer screening have rarely been studied (Padela et al., 2015). Such a study is especially crucial in a country like Iran, where $98 \%$ of the population identifies as Muslim, and religious and spiritual beliefs play a significant role in the outlooks and lives of Muslim Iranian women (Harandy et al., 2009).

Breast cancer screening strategies must thus acknowledge Muslim women's cultural context; however, there is little research on how religion shapes women's self-care understandings and practices. Specifically, despite the importance of the role of religious scholars and clergy in promoting health behaviors, there have been no studies thus far on the role of clergywomen in women's decision to pursue early detection measures. In a Muslim-majority country such as Iran, Muslim women's attitudes and religious beliefs regarding breast cancer prevention must be taken into account when designing educational programs, screening strategies, and interventions.

\section{Methods}

This article is part of a larger project on the comprehensive study of Iranian Muslim women's behaviors regarding breast cancer early detection measures, which employed qualitative frameworks and quantitative methods. The goal of the broader study was to design and implement an individualcentered educational model that promotes breast cancer prevention behaviors among Muslim women. In that study, breast cancer awareness campaigns as well as providing educational materials about breast self-examination, the early signs, and symptoms of breast cancer, alongside a national screening program of annual clinical breast examination, were found to be optimal strategies in Iran (Lamyian et al., 2007).

\section{Data Sample}

The study population consists of 25 women, ages 35 to 65 years old, who are residents of Tehran, Iran. It includes fifteen women at-risk for breast cancer and ten women with a history of breast cancer. At-risk is defined as having a history of breast cancer before the age of 40 in the family and was determined by women's self-reports. All of the women were Muslim and spoke Persian (Farsi). The women were chosen using purposive sampling. To capture greater insights, maximum variation was applied based on the type of education, age, socioeconomic status, and duration of seeking an early diagnosis. All interviews were conducted by the principal investigator, whose native language is Persian (Farsi). Table 1 provides a demographic description of the study sample.

\section{Data Collection}

Data were obtained through individual interviews with study participants. The techniques used by the researchers to ensure the accuracy of the information included bracketing and continuous immersion of data. All participants signed informed written consent prior to initiation of the study. Consent was also taken to record their voices. Moreover, the concepts of voluntary participation, anonymity, freedom to withdraw from the study without penalty, and explanation of the objectives and methodology of the study were explained to them .Interview settings included offices, clinics, private homes, and academic settings. The duration of each interview depended on the interest of the participant but typically lasted between 30 to 180 minutes, with an average time of 90 minutes. Interviews were semi-structured and conducted face-to-face. We asked open-ended questions where necessary in order to gain more insight into relevant topics. Participants were first asked demographic questions. Initial questions were followed by probing questions to elicit more detailed explanations or examples. For example, in regards to factors affecting their participation in screening measures, participants were asked: In your opinion, what is the meaning of cancer? Other questions included: Can you describe decisions you made in relation to your health? What are your main concerns about women's health care in Iran? Who has an impact on your self-care decisions? 
Questions were designed to discover and capture the complexity of women's interactions with healthcare services and perceptions about factors affecting their decisions to pursue breast cancer screening.

The researcher recorded her observations and thoughts immediately after the interview. Some of these topics helped the researcher to develop an interview guide over time (Polit \& Beck, 2006).

\section{Data Analysis}

Data analysis was conducted concurrently with the interviews. The qualitative content analysis method introduced by Granheim and Lundman (Graneheim \& Lundman, 2004) was used for data analysis. In the first step, the recorded audio data were turned into the text after each interview. Then, the researchers read the text of each interview several times to perceive an overall sense of the content. The whole text was considered as the unit of analysis. Next, words, sentences, or paragraphs containing aspects related to each other and the subject of the study were considered as meaning units. Then, the meaning units were coded according to the latent or explicit concept. The codes were condensed based on their similarities, and then the condensed codes were placed into subcategories and categories. To make the categories homogeneous internally and heterogeneous externally, constant comparisons of the codes, subcategories, and categories were used. By adjusting the categories through reflecting their underlying concepts, the themes emerged.

Data were analyzed using thematic analysis as it is particularly indicated for exploratory qualitative studies. It emphasizes pinpointing, examining, and recording patterns within data. Themes are patterns across data sets that are relevant to the description of a phenomenon and are associated with a specific research question (Strauss \& Corbin, 2008). All interviews were transcribed verbatim by a member of the research team. During the second stage of analysis, initial codes were reviewed and organized into broader categories. We then revisited the interviews and reorganized code clusters into related categories. Interviews were continued until data saturation was reached. The researcher used memos to analyze the data. All these steps were checked and discussed between research team members until unanimity was achieved. Codes and categories were then compared between all interviews. This method of analysis connected developing categories and captured the relationship between categories. While numerous categories emerged from the broader study, one of the key categories to emerge from this analysis was religion and specifically, the role of religious teachers in breast cancer prevention. In this paper, we address and analyze those codes and categories that pertain to the role of religion in women's decisions to pursue breast cancer screening measures.

For trustworthiness, the quality criteria based on Lincoln and Guba (Lincoln \& Guba, 1985) were considered. The researchers attempted to increase the credibility of the study by prolonging engagement with data extraction and interacting with the participants to ensure correct interpretation in the coding process (Strauss \& Corbin, 2008). External checking was considered for dependability by three experts, and peer checking was considered to establish confirmability. Sampling was designed to achieve maximum variation (Streubert \& Carpenter, 2011; Adatara et al., 2019).

\section{Results}

Below we summarize our findings from interviews with 25 women. We found that majority of women we spoke to lacked information about breast cancer screening and prevention, and that this information was often both a cause and effect of fear and misunderstandings about the process. However, awareness increased women's willingness to care for themselves.

Furthermore, we found that religious authorities, particularly clergywomen, who speak from a religious perspective, could play a significant and effective role in convincing women to pursue prevention measures. This identification is an achievement of this study regarding this theme.

Four major themes emerged from the data 
analysis which influenced women's decision to early detection. Themes are as follows: lack of information regarding breast cancer screening, awareness can improve self-care, religious outlooks of participants can influence early detection behaviors, and clergywomen can play a role in increasing awareness.

\section{Theme 1: Lack of Information Regarding Breast Cancer Screening}

A major barrier to women's pursuit of breast cancer screening is fear and ignorance regarding the screening process and its potential outcomes. Many participants acknowledged fear and doubts upon hearing the words 'breast cancer' and 'screening'. Such attitudes towards the causes of illness and screening methods affect their self-care behavior.

Factors that prevented active participation in disease prevention measures included lack of information about effective screening methods, as well as information about disease risk factors. As one participant diagnosed with breast cancer told us: 'I didn't even know what things might be dangerous for this illness, what things I should avoid. I also wasn't familiar with the tests done. I was 48 when I got sick and went to the doctor. He asked me if I have ever had a breast exam. I said no!' (Participant 25)

The majority of participants agreed that lack of information or misinformation regarding breast cancer screening, especially early detection, is an ongoing problem in Iranian society. In particular, many are misinformed about detection measures based on conversations with friends or relatives. One woman said: 'The majority of us aren't educated about these issues [early detection measure.] And if we know anything, we've heard it from our neighbor or friend. For example, they say that if you perform a breast self-exam, you'll get turned on. Or they say that mammography is very scary.' (Participant 13)

Other participants attested to this uncertainty regarding breast cancer screening: 'Usually I'm unsure whether to get a breast exam. I don't know whether there are good treatments for it like there are for other illnesses.' (Participant 21) Another woman said: 'In Iran, cancer means death. People hide it from each another, and if [cancer] patients find out exactly what they have, they'll quickly lose hope.' (Participant 23)

Some of the participants in contrast believed that fate and destiny had a role in the presentation of illness and that humans could not avoid their fate, including preventative measures. As one woman stated: 'I think that if I'm meant to get cancer, there's nothing I can do about it.' (Participant 5)

\section{Theme 2: Awareness Can Improve Self-Care}

Despite the lack of information regarding breast cancer screening for women, many women in our study pointed out the importance of increasing awareness about breast cancer screening. In particular, many participants in this study emphasized that respect and love for oneself, positive thinking, and individual proactivity can create a sense of responsibility for one's health, which, in turn, may lead to the pursuit of early detection measures. One woman expressed the following sentiment: 'We must value our own health.' (Participant 2)

The importance of self-responsibility, hope for life and understanding the value of one's health naturally result in a proactive approach to health and illness. Another woman said: 'Hope for life is the key to self-care about any problem.' (Participant 21) Women subscribing to this outlook had concluded that they shouldn't let cancer take hold.

Interlocutors also recognized that self-care could have significant benefits. In particular, the early detection of breast cancer could reduce the time, cost, and potential pain they might otherwise experience. One woman said: 'I also wasn't familiar with the tests [breast cancer early detection] done, but now I don't fear the test.' (Participant 24) Besides, trusting the capabilities of Iranian physicians to successfully treat breast cancer was a key element in reducing the fear of screening. Participants acknowledged that better education regarding breast cancer - especially, the 
knowledge that breast cancer could have a positive prognosis-increased their optimism and reduced their anxiety. As one woman stated: 'If I knew that breast cancer was treatable in modern medicine, I would do the test.' (Participant 17)

However, a major barrier to increasing awareness is a lack of publicity about the importance of preventative behaviors. Some women explained that knowledge from doctors, family, and friends served as a source of motivation, enhanced confidence, and lessened fears of performing preventive behaviors. However, the majority of women in our study were simply not exposed to information regarding preventive behaviors and screening, especially as their friends and family were similarly uninformed.

While media, including television, films, and magazines, may prove to be a positive factor in encouraging women to pursue breast cancer early detection, the influence of media in Iran is limited due to legal restrictions. As one participant suggested: 'Maybe because ours is an Islamic country, they don't allow [the media] to speak about this openly. But many families are struggling with this problem.' (Participant 8). Another corroborated this, saying: 'Radio and television don't refer to this issue very often so that we can be better informed. Doctors don't say anything either. How are we supposed to know what to do? If I figure out, I'll definitely do it.' (Participant 4). At least three other participants expressed similar sentiments about the limited information disseminated by media channels. (Participants 21, $3,17)$

These limitations highlight the need for alternative channels of dissemination for awareness messages. A major concern is the necessity of revisiting the socio-cultural limitations on open discussions of women's health, including breast health. As we shall see in the following section, many women emphasized that religious gatherings or framing health messages in a religious narrative could be a significant step forward in advocating early detection behaviors.

\section{Theme 3: Religious Outlooks of Participants} Can Influence Early Detection Behaviors

As all of our participants were Muslim women, many of them highlighted the importance of religious points of view in their approach to health. This was because, for many, religion is tied up with a belief in fate and trust in God's will. Participants identified trust in God as an important element in individuals' commitment to healthy behaviors. They also explained that belief in divine justice makes room for the calm acceptance of various prognoses. One woman said: 'We are responsible for our body; we should go to the doctor because it is a divine responsibility based on the divine teaching that humans should act [be proactive], and only then the help of God will come.' (Participant 23)

One member of the health team - a physician believed that the connection between religion and health could be presented in a more organized, standardized manner, saying, 'I think that in this matter, religious scholars should come to the aid of physicians.' (Participant 19). Another member of the health team, a nurse, agreed: 'It's better to discuss the issue of early detection of breast cancer from a religious perspective for women who gather in various religious settings. Until now, no one has used this approach. [Women] might be more motivated if this issue is approached both scientifically and religiously.' (Participant 9).

\section{Theme 4: Clergywomen Can Play a Role in} Increasing Awareness

Participants in the study recognized the importance of religious injunctions in promoting health, prevention, and wellness. They often highlighted the significant role that clerics, and in particular, clergywomen, have in this regard. The majority of women believed that clergywoman could address wellness topics and encourage preventative measures - in particular, early detection tests and follow-ups. These measures might have an important effect in institutionalizing such behaviors among Muslim women. One of the members of the health team, a midwife, 
commented: "How wonderful would it be if there were more emphasis on the religious requirement for women to maintain their health. If clergywomen [tāliba] speak more about health and hygiene, it would have a more of an influence.' (Participant 17) One woman stated: 'It would be good for them [clergywomen] to devote a portion of their lectures to humans' responsibilities in regards to their health and the how-to of health maintenance.' (Participant 15)

Given women's religious tendencies, mosques and religious gatherings, which serve as a venue for speakers to discuss the connection between health maintenance and religious ordinances, can play an important role in shaping individuals' outlook on illness. Religious gatherings, for many women, represent a missed opportunity for health care education, especially around early detection behaviors. Some of the participants in this study pointed out that they participated in many religious gatherings, but rarely encountered any discussion of religious ordinances regarding selfcare. One woman highlighted the importance of publicizing the need for early detection measures on the part of clergywomen: 'The majority of us think that only doctors should be saying this stuff, and because we don't trust doctors sometimes, we think they're saying it to make money. So we don't get the necessary tests done. I say - that's ok. I think that we should put up quotes on the wall in religious gatherings or pass out informational brochures. And clergywoman should emphasize these issues. It would be good for them to devote a portion of their lectures to people's responsibilities in regards to their health and the how-to of health maintenance.' (Participant 19)

It is especially important to note how participants contrasted their experiences with doctors and clergywoman. Women emphasized that clergywomen exhibit a more positive and sympathetic approach to health issues. As one woman said: '[Doctors] are very busy - they do not provide much advice. And it's possible that they're not very sympathetic. But clergywomen are truly pious individuals and they do think about saving people.' (Participant 12). Some women are even more likely to take recommendations from religious scholars and their study of religion rather than media or medical professionals. Two of the participants in the study made this point explicitly. A high school Religious Studies teacher said: 'Personally, I don't take doctors' recommendations very seriously. I would always say, they [doctors] change their words every day until I advanced in my study of religion and my religious beliefs were strengthened. Then I understood what was at hand. We are required to preserve our bodies and our lives. This issue should be discussed more in religious gatherings.' (Participants 9, 17).

On the rare occasions that clergywomen did speak out on health issues, their messages stood out. As one woman said: 'Recently, I attended a religious gathering in which the speaker $[a$ clergywoman] very briefly noted the following: If someone consciously or unconsciously causes herself to fall ill or does not take the necessary steps for recovery [from an illness], this individual, from a religious perspective, has not fulfilled her responsibilities.' (Participants 12)

Two other participants $(9,11)$ expressed similar sentiments. Such comments highlight the significant role that clergywoman can play in educating women about breast cancer prevention and screening measures.

Table 1. Participant characteristics

\begin{tabular}{lc} 
Characteristic & Frequency \\
\hline Marital status & \\
$\quad$ Married & 22 \\
$\quad$ Not married & 3 \\
Education & \\
$\quad$ Primary school & 10 \\
High school diploma & 8 \\
$\quad$ Higher education & 7 \\
Occupation & \\
$\quad$ Housewife ( stay home) & 15 \\
Employed & 10 \\
\hline
\end{tabular}

Notes: There were 25 participants in this study, with ages 35 to 65 years old. All participants were Muslim women living in Tehran. Not married status includes single, divorced, and widowed. 


\section{Discussion}

We found that participants in this study believe that prevention is a required religious ordinance. As such, we argue these links need to be publicized more broadly. Given that the maintenance and improvement of health is a necessary precondition to well-being and longevity, these topics are of particular significance in Islamic teachings. In Islam, health, in the broadest sense, is a virtue, but the preservation of life is [an Islamic] legal requirement (sharī'ah). As such, those actions that contribute to the preservation of life must rationally also be considered Islamic legal requirements.

These actions include measures taken for the early detection of illness. Religious teachings related to preventative care are based on three principles in the Islamic tradition: 1) the elevated status of human beings among God's creation, 2) the value of human life, both material/embodied and spiritual, 3) the teleology of creation. These principles underline the fact that it is inappropriate in Islam to disregard the importance of health. The Qur'an states that '...do not throw [yourselves] with your [own] hands into destruction...' (Yusuf Ali, 1983) which has been used by scholars to argue that self-harm, whether intentional or unintentional, is prohibited. Furthermore, in Islamic teachings, the preservation of health is both an individual and social responsibility. It is also attributed to Imam Ali, who is revered by Shia

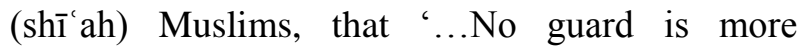
prudent than health... (Ghurar al-Hikam wa Durar al-Kalim, 2012).

From the Islamic perspective, humans are dualistic. In other words, there exists a mind-body division; however, mind and body are interdependent. Bodily health can positively impact spiritual health and vice versa. Furthermore, the Islamic outlook on mankind's place in God's creation holds humans responsible for the behaviors. Even though humans are influenced by environmental, social, and cultural factors, they are responsible for their destiny and are thus able to increase their knowledge and change their behaviors (Esfahani, 2009). Therefore, they are responsible for pursuing necessary measures for the maintenance of their physical health (Harandy et al.,2010; Harandy et al., 2009).

Moreover, the importance of preventative health measures can be derived from an inferential principle in Islamic juridical reasoning. According to this principle, precedent actions necessary to an obligatory action are themselves obligatory (Tavallaei, 2010). This principle has broad and significant implications. For instance, one can argue that if a Muslim is obligated to preserve physical health, then any preventive care becomes religiously required. We have inquired the official opinion [fatwā] of Grand Ayatollah Saanei, a renowned Shia cleric in Iran, about this argument. As figure 1 depicts, we asked 'wherever the preservation of life requires a preceding action, then those actions are rationally required. For example, there is a rational requirement for the preservation of human life, and this may include the use of medication, vaccinations, medical imaging. Thus, can we conclude that the preservation of health using preventative and early detection measures is rationally obligatory in Islamic law?'. His clear response is that 'saving one's life is indispensable and if the actions mentioned [preventive care] is a precedent to save lives, then it becomes rationally obligatory.'

Given these deep-seated Islamic teachings and principles, many of the participants in our study emphasized that they would pursue early detection measures if they were encouraged to do so from a religious point of view or by someone in a position of religious authority. Clarifying and publicizing the link between religious ordinances and health behaviors may strengthen women's participation in various health measures.

Limitations of this study include the fact that we only interviewed women living in the capital, Tehran. Hence, our study does not encompass the views of Iranian women in other regions and settings. Furthermore, as we only studied the perceptions of Muslim Iranian women, our 
findings may not apply to Iranian women who are religious minorities in Iran. Also, we relied on qualitative techniques rather than quantitative measures in this study.

Nevertheless, our findings reflect that of other recent research conducted on the relationship between religion and breast cancer prevention among women in other countries. In Somalia, women tended not to discuss breast cancer screening and held that religion played a central role in their decisions and coping mechanisms (Al-Amoudi et al., 2015). In Afghanistan, recent findings suggest a need for a community-based breast health education program that recognizes the unique social, cultural, and religious dynamics of the Muslim Afghan community (Shirazi et al., 2013). Also, American Muslims have low rates of mammography utilization, and research suggests that religious values influence their health-seeking behaviors (Padela et al., 2015).

This close tie between religious belief and health is not unique to Islam or Iran. Studies reveal that there is a meaningful relationship between religious beliefs and health, and some even conclude that there is a causal relationship between religious involvement and individuals' health (Levin \&Taylor, 1998). Other studies have observed that membership in religious groups that are highly integrated and regulated motivates participants to live a healthy lifestyle (Bailey et al, 2000). Traditional Protestant groups demand that their followers adhere to certain moral and behavioral standards as a sign of their religious commitment. This includes prohibitions against sexual relations before marriage, which itself serves as a preventative measure in the transmission of STDs. Furthermore, the existence of interpersonal relationships and strong social networks contribute to the prevention of certain illnesses among members of faith communities. Such networks have been observed among Mormons, Jews, and certain Christian denominations, such as Seventh Day Adventists. A study in Jordan recommended that culturally appropriate training for Muslim religious leaders in Jordan can lead to better engagement with various health issues, including reproductive health and family planning (Underwood et al., 2013). However, thus far, the role of female religious leaders has been overlooked.

According to the Director of the Women's Seminaries in Iran, Islamic educational units for women (Howzeh Elmieh Khaharan) have expanded to almost 500 units across the country during the past two decades. Meanwhile, the number of graduates has reached 100,000 while about 90,000 female students are currently enrolled in Iran's seminaries (Reviewing 20 years of Women's Seminaries in Iran, 2019). These numbers are quite significant. Female religious scholars are a significant part of the daily lives of Muslim women as they interact face-to-face with women and provide education on several topics. They deliver hundreds of presentations each year. As such, they are uniquely positioned to influence women's decision to pursue screening measures using an effective tool which we call informed persuasion. Informed persuasion is a process by which women can be convinced to pursue preventative measures through exposure to accurate, up-to-date information in a manner relevant to their background knowledge and beliefs. This can be achieved through the use of knowledge, art, and various modalities (or educational strategies) to connect to women. Such educational frameworks have been developed in other contexts with success - researchers at the University of Alabama at Birmingham developed an educational booklet on breast cancer early detection from within a spiritual framework and found that a spiritually-based approach may be more effective than a purely secular one (Holt \& Klem, 2005).

\section{Ethical Considerations}

The research protocol was approved by the Institutional Review Board (IRB) of Tarbiat Modares University (TMU). The main researcher contacted each of the potential participants and 
informed them of objectives, team members, study methods, and the need for audio recordings of interviews. Participants were also guaranteed confidentiality, anonymity, and the right to withdraw from the study at any time. If the participant agreed to take part in the research, an interview was scheduled. All participants provided written informed consent.

\section{Conclusion}

Understanding women's perception about screening and early detection of breast cancer is essential for policymakers and healthcare providers to design culturally appropriate and ageappropriate health promotion campaigns and services.

Thus, all in all, we make the following argument; to increase women's active and selfaware participation in breast cancer early detection measures in Iran, religious gatherings, and clergywomen who particularly play an important role. We, therefore, argue that clergywomen in Iran, of which there are over 90,000 , can play a significant role in encouraging women to pursue breast cancer screening in the country. Others studying the Muslim world have highlighted the importance of religious leaders in promoting health behaviors as well.

We suggest that for future campaigns, clergywomen in Iran employ the tool of informed persuasion, which could be used as a new and effective way of health promotion, to convince women of the religious value of pursuing breast cancer screening.

\section{Conflict of interest}

The authors in this study have reported no conflict of interest.

\section{Acknowledgments}

The authors thank Tarbiat Modares University for supporting this project and also express their gratitude to all the women who participated in this study.

\section{Author contribution}

Conceptualization, M.L. and F.A.; Methodology,
H.Sh. and M.L.; Investigation, M.L.; Writing original draft, F.A.; Writing - review and editing, M.L.; Resources, F.A.; Supervision, M.L.

All authors read and approved the final manuscript and are responsible about any question related to the article.

\section{References}

Alianmoghaddam, N., Khoshnood, K., Benn, C., Kennedy, H. P., Lamyian, M. (2017). Breast Cancer, Breastfeeding, and Mastectomy: A Call for More Research. Journal of Human Lactation, 33(2), 454-457. doi:10.1177/0890334416678822

Adatara, P., Strumpher, J., Ricks, E., MwiniNyaledzigbor, P. P. (2019). Cultural beliefs and practices of women influencing home births in rural Northern Ghana. International journal of women's health, 11, 353-361. doi:10.2147/ IJWH.S 190402

Al-Amoudi, S., Cañas, J., Hohl, S. D., Distelhorst, S. R., Thompson, B. (2015). Breaking the silence: breast cancer knowledge and beliefs among Somali Muslim women in Seattle, Washington. Health care for women international, 36(5), 608-616. doi:10.1080/ 07399332.2013 .857323

Anderson, B.O., Yip, C.H., Smith, R.A., et al. (2008). Guideline implementation for breast healthcare in low-income and middle-income countries: Overview of the Breast Health Global Initiative Global Summit 2007. Cancer, 113(8 Suppl), 2221-2243. doi:10.1002/cncr.23844

Babu, G. R., Samari, G., Cohen, S. P., Mahapatra, T., Wahbe, R. M., Mermash, S., Galal, O. M. (2011). Breast cancer screening among females in Iran and recommendations for improved practice: a review. Asian Pacific Journal Cancer Prevention, 12(7), 1647-1655.

Bray, F., Ferlay, J., Soerjomataram, I., Siegel, R. L., Torre, L. A., Jemal, A. (2018). Global cancer statistics 2018: GLOBOCAN estimates of incidence and mortality worldwide for 36 cancers in 185 countries. Cancer Journal for Clinicals, 68(6), 394-424. doi:10.3322/caac. 21492 
Bailey, E. J., Erwin, D. O., Belin, P. (2000). Using cultural beliefs and patterns to improve mammography utilization among AfricanAmerican women: the Witness Project. Journal of the National Medical Association, 92(3), 136142.

Cancer Country Profiles [homepage on the Internet]. Geneva: World Health Organization; 2016. Available from: https://www.who.int/ cancer/country-profiles/irn_en.pdf?ua=1.

Accessed February 7, 2016.

Cancer Facts \& Figures [homepage on the Internet]. Atlanta: American Cancer Society; 2018. Available from: https://www.cancer.org/ research/cancer-facts-statistics/. Accessed June 10, 2019.

Esfahani, M. (2009). Health Rituals. 9th ed. Tehran: Tandis Publishing Co. [Persian]

Ferlay, J., Colombet, M., Soerjomataram, I., Mathers, C., Parkin, D.M., Piñeros, M., Znaor, A., Bray, F. (2019). Estimating the global cancer incidence and mortality in 2018: GLOBOCAN sources and methods. International journal of cancer,144(8), 1941-1953. doi:10.1002/ijc.31937

Ferlay, J., Soerjomataram, I., Dikshit, R., Eser, U., Mathers, C., Rebelo, R., Parkin, D.M., Forman, D., Bray, F. (2015). Cancer incidence and mortality worldwide: sources, methods and major patterns in GLOBOCAN 2012. International journal of cancer, 136(5), E359-E386. doi:10.1002/ijc.29210

Ghurar al-Hikam wa Durar al-Kalim [Exalted Aphorisms and Pearls of Speech]. (2012). Qum (Iran): Ansariyan Publications; Arabic.

Graneheim, U.H., Lundman, B. (2004). Qualitative content analysis in nursing research: concepts, procedures and measures to achieve trustworthiness. Nurse Education Today, 24(2), 105-112.

Harirchi, I., Ebrahimi, M., Zamani, N., Jarvandi, S., Montazeri, A. (2000). Breast cancer in Iran: a review of 903 case records. Public health, 114(2), 143-145. doi:10.1038/sj.ph.1900623

Haghighi, S. T., Lamyian, M., Granpaye, L. (2015). Assessment of the level of health literacy among fertile Iranian women with breast cancer. Electronic physician, 7(6), 1359-1364. doi:10.14661/1359

Harandy, T. F., Ghofranipour, F., Montazeri, A., Anoosheh, M., Mohammadi, E., Ahmadi, F., Niknami, S. (2010). Health-related quality of life in Iranian breast cancer survivors: a qualitative study. Applied Research in Quality of Life, 5(2), 121-132. doi:10.1007/s11482-010-9097-3

Harandy, T. F., Ghofranipour, F., Montazeri, A., Anoosheh, M., Bazargan, M., Mohammadi, E., Niknami, S. (2009). Muslim breast cancer survivor spirituality: coping strategy or health seeking behavior hindrance?. Health care for women international, 31(1), 88-98. doi:10.1080/07399330903104516

Harirchi, I., Ghaemmaghami, F., Karbakhsh, M., Moghimi, R., Mazaherie, H. (2005). Patient delay in women presenting with advanced breast cancer: an Iranian study. Public Health, 119(10), 885-891. doi:10.1016/j.puhe.2004.11.005

Heydari, S.T., Mehrabani, D., Tabei, S.Z., Azarpira, N., Vakili, M.A. ( 2009). Survival of breast cancer in southern Iran. Iran Journal Cancer Prevention, 2, 51-4.

Holt, C. L., Klem, P. R. (2005). As you go, spread the word: spiritually based breast cancer education for African American women. Gynecologic Oncology, 99(3), S141-S142.

Khazaee-Pool, M., Montazeri, A., Majlessi, F., Foroushani, A. R., Nedjat, S., Shojaeizadeh, D. (2014). Breast cancer-preventive behaviors: exploring Iranian women's experiences. BMC women's health, 14(1), 1-9. doi:10.1186/14726874-14-41

Lamyian, M., Ahmadi, F., Faghihzadeh, S., Aguilar Vafaie, M. E. (2007). Barriers to and factors facilitating breast cancer screening among Iranian women: a qualitative study. EMHJ-Eastern Mediterranean Health Journal, 13 (5), 1160-1169, 2007.

Levin, J. S., Taylor, R. J. (1998). Panel analyses of religious involvement and well-being in African Americans: Contemporaneous vs. longitudinal effects. Journal for the Scientific Study of 
Religion, 37(4), 695-709. doi:10.2307/1388151

Lincoln, Y.S., Guba, E.G. (1985). Naturalistic Inquiry. Sage Publications, Beverly Hills.

Movahedi, M., Haghighat, S., Khayamzadeh, M., Moradi, A., Ghanbari-Motlagh, A., Mirzaei, H., Esmail-Akbari, M. (2012). Survival rate of breast cancer based on geographical variation in Iran, a national study. Iranian Red Crescent Medical Journal, 14(12), 798-804.

Mousavi, S. M., Mohagheghi, M. A., MousaviJerrahi, A., Nahvijou, A., Seddighi, Z. (2008). Outcome of breast cancer in Iran: a study of Tehran Cancer Registry data. Asian Pacific journal of cancer prevention, 9(2), 275-278.

Mousavi S.M., Montazeri, A., Mohagheghi, M.A., Mousavi Jarrahi, A., Harirchi, I., Najafi,M., Ebrahimi, M. (2007). Breast cancer in Iran: An epidemiological review. The Breast Journal ,13(4), 383-391. doi:10.1111/j.1524-4741.2007. 00446.x

Moodi, M., Rezaeian, M., Mostafavi, F., Sharifirad, G. R. (2012). Mammography stage of adoption among Iranian women. Journal of education and health promotion, 1 . doi:10.4103/2277-9531.102050

Mousavi-Jarrrahi, S. H., Kasaeian, A., Mansori, K., Ranjbaran, M., Khodadost, M., Mosavi-Jarrahi, A. (2013). Addressing the younger age at onset in breast cancer patients in Asia: an age-periodcohort analysis of fifty years of quality data from the international agency for research on cancer. International Scholarly Research Notices, 2013. doi:10.1155/2013/429862

Montazeri, A., Ebrahimi, M., Mehrdad, N., Ansari, M., Sajadian, A. (2003). Delayed presentation in breast cancer: a study in Iranian women. BMC women's health, 3(1), 1-6. doi:10.1186/14726874-3-4

Noroozi, A., Jomand, T., Tahmasebi, R. (2011). Determinants of breast self-examination performance among Iranian women: an application of the health belief model. Journal of Cancer Education, 26(2), 365-374. doi:10.1007/s13187-010-0158-y

Nasirzadeh, R., Rassolzadeh Tabatabaie, K.
(2009). Religious beliefs and coping strategies in students. Ofogh-e-Danesh, 15(2), 36-45. [Persian]

Padela, A.I., Murrar, S., Adviento, B., Liao, C., Hosseinian, Z., Peek, M., Curlin, F. (2015). Associations between religion-related factors and breast cancer screening among American Muslims. Journal Immigr Minor Health, 17(3), 660-669. doi:10.1007/s10903-014-0014-y

Perry, S., Kowalski, T. L., Chang, C. H. (2007). Quality of life assessment in women with breast cancer: benefits, acceptability and utilization. Health and Quality of life Outcomes, 5(1), 1-14. doi:10.1186/1477-7525-5-24

Polit, D.F., Beck, C.T. (2006). Essentials of Nursing Research, Methods, Appraisal and Utilization. 6th ed. Philadelphia (PA): Lippincott Williams \& Wilkins.

Rezaianzadeh, A., Heydari, S. T., Hosseini, H., Haghdoost, A. A., Barooti, E., Lankarani, K. B. (2011). Prevalence of breast cancer in a defined population of Iran. Iranian Red Crescent Medical Journal, 13(9), 647-650.

Reviewing 20 years of Women's Seminaries in Iran. Fars News Agency. 2018 Jan 8; [home page on the Internet]. Available from: http://fna.ir/ a3a3jz. Accessed: June 13, 2019. [Persion]

Shulman, L. N., Willett, W., Sievers, A., Knaul, F. M. (2010). Breast cancer in developing countries: opportunities for improved survival. Journal of oncology, 2010. doi:10.1155/2010/ 595167.

Strauss, A., Corbin, J. (2008). Basics of Qualitative Research (3rd ed.): Techniques and Procedures for Developing Grounded Theory.

Streubert, H., Carpenter, D. (2011). Qualitative research in nursing: Advancing the humanistic imperative. Fifth ed. Philadelphia: Wolters Kluwer Health/Lippincott Williams \& Wilkins.

Shirazi, M., Bloom, J., Shirazi, A., Popal, R. (2013). Afghan immigrant women's knowledge and behaviors around breast cancer screening. Psycho-Oncology, 22(8), 1705-1717. doi:10. 1002/pon.3216

Tavallaei, A. (2010). Historical Background of 
Obligatory Preliminary (Moghadamaye Vajib) in Islamic Jurisprudence. Jurisprudence the Essentials of the Islamic Law, 43(1), 31-56.

Underwood, C., Kamhawi, S., Nofal, A. (2013). Religious leaders gain ground in the Jordanian family-planning movement. International Journal of Gynecology \& Obstetrics, 123, e33-e37.

Yusuf Ali, A. (1983). The Holy Qur'an: Text, Translation and Commentary. Brentwood (MD): Amana Corp. 